\title{
Carbon Emissions and Carbon Intensity in China's Exports: A Contrast of SRIO and GIRIO Methods
}

\author{
Hao XIAO \\ School of Economics and Trade, Hunan University, Changsha 410079, China \\ E-mail: xh_26@126.com \\ Jianguo WANG \\ School of Economics and Trade, Hunan University, Changsha 410079, China \\ E-mail: wangjianguo1992@gmail.com \\ Qiao ZHU \\ School of Economics and Trade, Hunan University, Changsha 410079, China \\ E-mail: pretty223@126.com
}

Han QIAO

School of Economics and Management, University of Chinese Academy of Sciences, Beijing 100190, China

E-mail: qiaohan@amss.ac.cn

\begin{abstract}
This paper compares differences between single regional input-output (SRIO) model and global inter-regional IO model (GIRIO) used in the area of carbon emission embodied in exports under global supply chain, and decomposes carbon emissions and carbon intensity in exports according to export path based on KWW (2014). Empirical analysis in China's exports in 1995, 2000, 2005 and 2009 shows: 1) GIRIO model yielded about $2.11 \%$ less domestic emissions absorbed abroad, $0.8 \%$ more domestic emissions in exports, 1.5 times more foreign emissions in exports in 2009, compared to SRIO model. 2) USA and EU absorb most carbon emissions in China's exports, but with declining share. Increasing domestic emissions firstly exported to developing countries but finally returned home and emissions from developing countries in China's exports show their contribution from developing countries. Discrepancies between bilateral carbon emissions flows changes and direct trade flows changes suggest indirect carbon emissions transfer by third parties are neglected in SRIO model. 3) Despite dramatic decrease, China still bears 1.52 times more carbon emissions per GDP gained than foreign countries in fragmentation of China's exports production in 2009, indicating different roles in production fragmentation.
\end{abstract}

Keywords carbon emissions; carbon intensity; GIRIO model; SRIO model

Received March 24, 2015, accepted July 22, 2015

Supported by the National Natural Social Science Foundation of China (71203062, 71203062, 71003057, $71373262)$ 


\section{Introduction}

After more than thirty years of opening-up, China has become the world's largest exporter and the second largest importer. Meanwhile, China also has become the world's largest greenhouse gases emitter. However, one important feature of global trade is that a country's carbon footprints are international. With the imbalance of carbon emission efficient and trade across countries, some policies like carbon tariff and global carbon market has become a hot topic in the area of trade and environment ${ }^{[1]}$. Accurate estimation of carbon emissions embodied in trade is primary for allocating carbon emissions reduction responsibility, especially consumerbased and producer-based responsibility. For example, carbon leakage from Kyoto Protocol is $10.8 \%$ of total domestic emissions, and $44.3 \%$ of total emissions in imports from non-Annex B countries $^{[2]}$.

The most common methodology to study carbon emissions embodied in trade is inputoutput analysis, for capturing both direct and indirect emissions with exports production. Those literatures are mainly divided into two types: single regional IO models (SRIO) and multiregional IO model (MRIO). Non-competitive SRIO model clarifies imperfect substitutability between imported intermediate goods and domestic intermediate goods, which is more popular to study carbon emission in China's gross trade ${ }^{[3-5]}$, emission in China's bilateral trade ${ }^{[6,7]}$. However, SRIO model does not distinguish sources of imported intermediate inputs and technology differences among imported products ${ }^{[8,9]}$. The production function assumes that all imported intermediate inputs must contain 100\% foreign value added (carbon emissions), i.e. no indirect domestic content in imports ${ }^{[10]}$. Under global fragmentation, imports contain imported inputs from all countries, including itself, when exports partly return home after re-processing. In addition, SRIO model fails to capture indirect carbon emissions flows via third countries and feedback effects that occur when intermediate trade prevails ${ }^{[11,12]}$.

MRIO model addresses those shortcomings in SRIO model ${ }^{[13]}$. When comparing MRIO and SRIO allocation ${ }^{[9]}$, found differences of $5 \% \sim 6 \%$ for US carbon emissions in exports and $11 \% \sim 13 \%$ for its carbon emissions in imports between 1994 and 2004. The difference could be excess of $20 \%$ for some countries, depending on trade structures ${ }^{[14]}$. Also it indicated increased emissions exports from China and emerging countries to developed countries ${ }^{[15]}$. By improvement in detailed information on inter-regional, inter-sector supply and demand information, GIRIO model is more effective to estimate international production sharing ${ }^{[10,16,17]}$, emissions embodied in trade ${ }^{[18-20]}$.

A key technical framework KWW by [10] based on GIRIO model, completely decomposed gross exports to value-added components by origins and final destinations: domestic valueadded exports, returned domestic value-added in exports, foreign value-added in exports. It traces actual value-added flows under gross trade. Results indicate domestic value-added accounted for less than $50 \%$ of China's processing exports, and trade surplus with the US and Western EU measured in value-added terms was 41\%, 49\% less than that measured in gross terms in 2004. Similarly, under global production fragmentation, estimation of carbon emissions in gross exports diverges from actual carbon emissions flows. Considering the fact that domestic emissions may firstly "exported" but finally "return" home via re-imports, how much carbon emissions actually absorbed by foreign countries? Also, carbon emissions in direct exports may 
further transferred to third countries, what is actual bilateral carbon leakage? Accurate analysis of these special features requires estimating carbon emissions in exports under GIRIO model.

Furthermore, how much environmental cost each country' bears per GDP created under exports production fragmentation? Considering different emissions flows, value-added flows required directly and indirectly by different final demands, it is worth to estimate embodied carbon intensity by "demand" side, i.e., embodied carbon intensity induced by consumption, exports, investment of each economy ${ }^{[21]}$, although most studies merely estimate carbon intensity directly from "producer" side. As both matters, we estimate embodied carbon intensity by origin by destination in different exports fragmentation processes.

Following the framework by [10], this paper decomposes carbon emissions and carbon intensity in export by origins and destinations in GIRIO model, compares the differences with SRIO approach, and empirically estimates emissions in China's exports in 1995, 2000, 2005 and 2009. Main contributions include: 1) Extending KWW framework to decompose carbon emissions in exports according to its export path at national, bilateral level, and systematically compares differences between SRIO model and GIRIO model in analyzing carbon emissions in exports; 2) Bilateral analysis specifies each trade partner's absorption of China's domestic emissions, contribution to returned domestic emissions and their emissions induced by China's exports. Cross country comparison shows their different roles in carbon emissions distribution; 3) By joining value-added accounts and carbon emissions accounts, promote embodied domestic and foreign carbon intensity in exports, to measure environmental cost per GDP gained in exports production fragmentation.

\section{Methodology}

\subsection{Carbon Emissions and Carbon Intensity in Exports in SRIO Model}

In standard SRIO model, suppose $S$ as object country, with $n$ industries. Assume $A_{D}$ as direct input coefficients matrix of domestic products, $A_{M}$ as direct input coefficients matrix of imported products, $v_{S}$ as value-added coefficient vector. Exports $E x_{S}$ includes domestic valueadded in exports $D V_{S}^{\mathrm{SRIO}}$, foreign value-added in exports $F V_{S}^{\mathrm{SRIO}}$, i.e., foreign value-added embodied in imported intermediate inputs required for export production.

$$
\begin{aligned}
& D V_{S}^{\text {SRIO }}=v_{S}\left(I-A_{D}\right)^{-1} E x_{S} \\
& F V_{S}^{\text {SRIO }}=v_{S} A_{M}\left(I-A_{D}\right)^{-1} E x_{S}
\end{aligned}
$$

Similarly, carbon emissions in exports include domestic carbon emissions in exports $D C_{S}^{\mathrm{SRIO}}$ and foreign emissions in exports $F C_{S}^{\mathrm{SRIO}}$, where $c_{S}$ is carbon emissions coefficient vector.

$$
\begin{aligned}
& D C_{S}^{\mathrm{SRIO}}=c_{S}\left(I-A_{D}\right)^{-1} E x_{S} \\
& F C_{S}^{\mathrm{SRIO}}=c_{S} A_{M}\left(I-A_{D}\right)^{-1} E x_{S}
\end{aligned}
$$

Environmental cost per GDP created in export production is calculated by combining corresponding value-added terms and carbon emissions terms: embodied domestic carbon intensity in exports $D E_{S}^{\mathrm{SRIO}}$, embodied foreign carbon intensity in exports $F E_{S}^{\mathrm{SRIO}}$,

$$
D E_{S}^{\mathrm{SRIO}}=\frac{D C_{S}^{\mathrm{SRIO}}}{D V_{S}^{\mathrm{SRIO}}}
$$




$$
F E_{S}^{\mathrm{SRIO}}=\frac{F C_{S}^{\mathrm{SRIO}}}{F V_{S}^{\mathrm{SRIO}}}
$$

\subsection{Carbon emissions and carbon intensities in exports in GIRIO model}

Assume there are $G$ countries, each with $n$ industries. Suppose $S$ as object country (exporter), and $R, T$ as any other countries. GIRIO model covers worldwide interregional, intersector supply-demand linkages, that is, imported production distinguished by country source. Suppose $Y_{S R}$ as country $R$ 's final demand of country $S^{\prime}$ s products, $A$ as direct input coefficient, $B$ as Leontief coefficient matrix. $v$ is direct value-added coefficient vector, $c$ is direct carbon emissions coefficient vector.

Under global intermediate trade, direct importer is not always the final destination of exported goods, and direct exports are not always the origin of exported products. By transforming endogenous intermediate trade in GIRIO model to terms induced by exogenous final demand, a key technical step by (7) decomposed gross exports flows to value-added flows by origins by final destinations ${ }^{[10]}$ : (a) Domestic value-added exports $D V X_{S}^{\text {GIRIO }}$, i.e. domestic value-added finally absorbed abroad; (b) Domestic value-added in intermediate exports that finally returns home $D R V_{S}^{\text {GIRIO }}$ (c) Foreign value-added in supplying imported inputs $F V_{S}^{\text {GIRIO }}$. It bridges official direct trade data with value-added flows.

$$
E_{S *}=D V X_{S}^{\mathrm{GIRIO}}+D R V_{S}^{\mathrm{GIRIO}}+F V_{S}^{\mathrm{GIRIO}}
$$

Similarly, carbon emissions in $S^{\prime}$ exports can also be decomposed by original producers by final destinations along global supply chains. Carbon emissions in $S^{\prime}$ exports $C E E_{S^{*}}$ :

$$
C E E_{S^{*}}=D C X_{S}^{\mathrm{GIRIO}}+D R C_{S}^{\mathrm{GIRIO}}+F C_{S}^{\mathrm{GIRIO}}
$$

(a) Domestic carbon emission exports $D C X_{S}^{\mathrm{GIRIO}}$, namely domestic emissions finally absorbed abroad:

$$
D C X_{S}^{\mathrm{GIRIO}}=c_{S} \sum_{R \neq S}^{G} B_{S S} Y_{S R}+c_{S} \sum_{R \neq S}^{G} B_{S R} Y_{R R}+c_{S} \sum_{R \neq S}^{G} \sum_{T \neq S, R}^{G} B_{S R} Y_{R T}
$$

(9) include $S^{\prime}$ domestic emissions in final exports to $R$ absorbed by $R$ (1st term), in intermediate exports to $R$ absorbed by $R$ (2nd term), and in intermediate exports to $T$ for production of final products absorbed by $R$ (3rd term), involving indirect carbon emissions exports via third parties.

Specifically $S^{\prime}$ domestic emissions exports to country $R$ :

$$
D C X_{S R}^{\mathrm{GIRIO}}=c_{S} B_{S S} Y_{S R}+c_{S} B_{S R} Y_{S R}+c_{S} \sum_{T \neq S, R}^{G} B_{S T} Y_{T R}
$$

(b) Domestic emissions in intermediate exports but finally returns home $D R C_{S}^{\mathrm{GIRIO}}$.

$$
\begin{aligned}
D R C_{S}^{\mathrm{GIRIO}}= & c_{S} \sum_{R \neq S}^{G} B_{S R} Y_{R S}+c_{S} \sum_{R \neq S}^{G} B_{S R} A_{R S}\left(I-A_{S S}\right)^{-1} Y_{S S} \\
& +c_{S} \sum_{T \neq S}^{G} B_{S R} A_{R S}\left(I-A_{S S}\right)^{-1} Y_{S S} E_{S^{*}}
\end{aligned}
$$


Specifically $R^{\prime} s$ contribution in returned emissions in $S^{\prime}$ exports:

$$
D R C_{S R S}^{\mathrm{GIRIO}}=c_{S} B_{S R} Y_{R S}+c_{S} B_{S R} A_{R S}\left(I-A_{S S}\right)^{-1} Y_{S S}+c_{S} B_{S R} A_{R S}\left(I-A_{S S}\right)^{-1} E_{S^{*}}
$$

(11) and (12) include $S^{\prime}$ domestic emissions in intermediate exports to R but returns home via final imports (1st term), via intermediate imports (2nd term), and domestic emissions in intermediate exports to $\mathrm{R}$, then return home via intermediate imports but then exported, also double counted term but belongs to domestic emissions in exports (3rd term).

Domestic emissions in exports $D C_{S}^{\mathrm{GIRIO}}$ include domestic carbon emissions exports $D C X_{S}^{\mathrm{GIRIO}}$ and domestic emissions firstly exported but finally returned home $D R C_{S}^{\mathrm{GIRIO}}$.

$$
D C_{S}^{\mathrm{GIRIO}}=D C X_{S}^{\mathrm{GIRIO}}+D R C_{S}^{\mathrm{GIRIO}}
$$

(c) Foreign carbon emissions in $S^{\prime}$ exports $F C_{S}^{\text {GIRIO }}$

$$
\begin{aligned}
F C_{S}^{\text {GIRIO }}= & \sum_{R \neq S}^{G} c_{T} B_{T S} Y_{S R}+\sum_{R \neq S}^{G} c_{T} B_{T S} Y_{S R} A_{S R}\left(I-A_{R R}^{-1}\right) Y_{R R} \\
& +\sum_{T \neq S}^{G} \sum_{T \neq S, R}^{G} c_{T} B_{T S} A_{S R}\left(I-A_{R R}^{-1}\right) E_{R^{*}}
\end{aligned}
$$

Specifically $T^{\prime} s$ carbon emissions in $S^{\prime}$ exports $F C_{T S}^{\mathrm{GIRIO}}$ :

$$
\begin{aligned}
F C_{T S}^{\mathrm{GIRIO}}= & \sum_{R \neq S}^{G} c_{T} B_{T S} Y_{S R}+\sum_{R \neq S}^{G} c_{T} B_{T S} Y_{S R} A_{S R}\left(I-A_{R R}^{-1}\right) Y_{R R} \\
& +\sum_{T \neq S}^{G} c_{T} B_{T S} A_{S R}\left(I-A_{R R}^{-1}\right) E_{R^{*}}
\end{aligned}
$$

(14) and (15) include $T^{\prime}$ emissions in intermediate exports to $S$ for producing $S^{\prime}$ final exports absorbed abroad (1st term), for producing $S^{\prime}$ intermediate exports absorbed abroad (2nd term), for producing $S^{\prime}$ intermediate exports then used by $R$ to producing $R^{\prime}$ exports, also double-counted but belongs to foreign emissions in exports (3rd term).

Above decomposition shows value-added distribution and carbon emissions transfer among countries in exports production. Combing value-added and emissions accounting by origin by destination, calculate each country's potential environment cost per value-added gained, i.e. embodied carbon intensity of each component, which indicates different participation in exports production fragmentation.

Then, embodied domestic carbon intensity in exports absorbed abroad $D E X_{S}^{\text {GIRIO }}$, embodied domestic carbon intensity in return part $D R E_{S}^{\mathrm{GIRIO}}$, and embodied foreign carbon intensity in exports $F E_{S}^{\mathrm{GIRIO}}$.

$$
\begin{aligned}
& D E X_{S}^{\mathrm{GIRIO}}=\frac{D C X_{S}^{\mathrm{GIRIO}}}{D V X_{S}^{\mathrm{GIRIO}}} \\
& D R E_{S}^{\mathrm{GIRIO}}=\frac{D R C_{S}^{\mathrm{GIRIO}}}{D R V_{S}^{\mathrm{GIRIO}}} \\
& F E_{S}^{\mathrm{GIRIO}}=\frac{F C_{S}^{\mathrm{GIRIO}}}{F V_{S}^{\mathrm{GIRIO}}}
\end{aligned}
$$


Overall domestic carbon intensity in exports $D E_{S}^{\mathrm{GIRIO}}$ are shown as follow.

$$
D E_{S}^{\mathrm{GIRIO}}=\frac{\left(D C X_{S}^{\mathrm{GIRIO}}+D R C_{S}^{\mathrm{GIRIO}}\right)}{\left(D V X_{S}^{\mathrm{GIRIO}}+D R V_{S}^{\mathrm{GIRIO}}\right)}
$$

Figure 1 show the overall extending KWW framework of value-added, carbon emissions, and carbon intensities accounting of gross export.

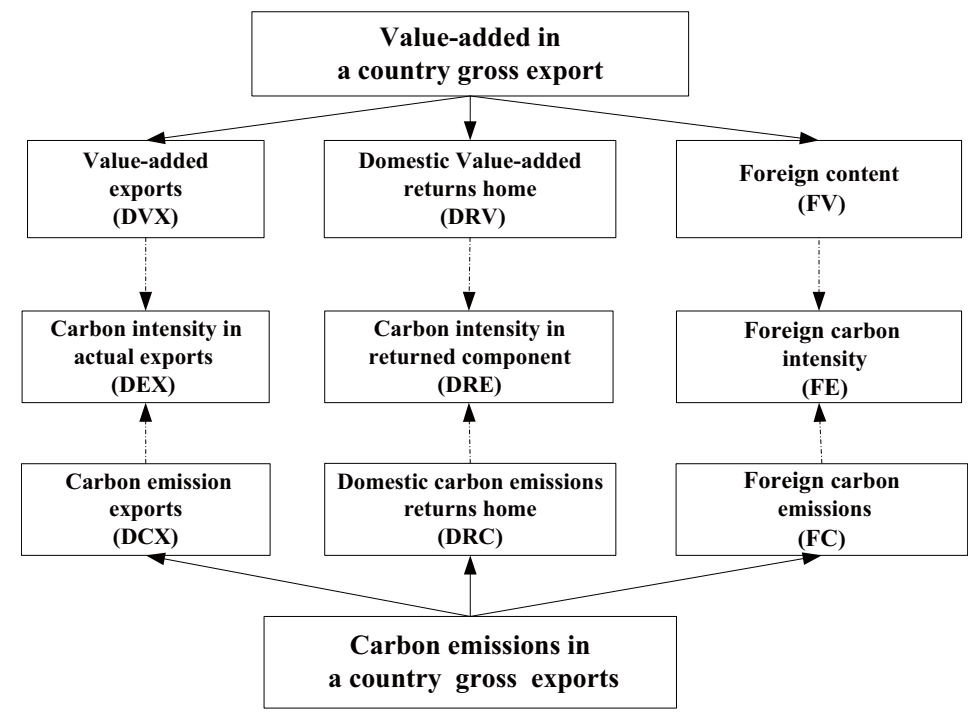

Figure 1 Value-added, carbon emissions, and carbon intensities accounting of gross exports

\subsection{Contrast of SRIO and GIRIO Model in Exports Analysis}

SRIO model mainly specifies domestic production while GIRIO model captures global interregional inter-sector linkages. Different scopes in Leontief matrix, intermediate and final trade flows thus affect estimation of carbon emissions and carbon intensities embodied in exports.

Specially, based on the assumption that all imported intermediates contain $100 \%$ foreign content, i.e., no domestic emissions that initially exported but returned home via intermediate imports $D R C_{S}^{\mathrm{GIRIO}}$, SRIO model underestimates domestic emissions in exports $D C_{S}^{\text {GIRIO, }}$ confuses carbon emissions exports $D C X_{S}^{\mathrm{GIRIO}}$ with $D C_{S}^{\mathrm{SRIO}}$, and mistakes foreign emissions in exports $F C_{S}^{\text {GIRIO }}$ with domestic emissions avoided by imports $F C_{S}^{\text {SRIO }}$, compared with GIRIO analysis.

Furthermore, when more than one country export intermediate products, direct importer is not always the final destination, and direct exporter is not always the origin of value-added and carbon emissions in exports. SRIO model merely considers direct trade. By contrast, GIRIO model estimates bilateral carbon emissions flows $D C X_{S R}^{\mathrm{GIRIO}}, D R C_{S R S}^{\mathrm{GIRIO}}, F C_{T S}^{\mathrm{GIRIO}}$ in direct trade and indirect trade via third parties by tracing their origins and destinations of emissions. As domestic emissions in intermediate exports to developing countries may be finally absorbed by developed countries, and imports from developed countries may contain quantitative emissions from developing countries, SRIO analysis potentially underestimates carbon emissions exports to the developed countries while overestimate embodied emissions in exports from the developing countries. 
As for environment losses per GDP gained in exports production fragmentation, SRIO model estimates $D E_{S}^{\mathrm{SRIO}}$ in (5) and $F E_{S}^{\mathrm{SRIO}}$ in (6), the last of which is actually domestic emissions avoided per value-added reduced by imports. Combining "trade in value-added" and "trade in $\mathrm{CO}_{2}$ emissions" accounts, GIRIO model estimates embodied carbon intensity in each component $D E X_{S}^{\mathrm{GIRIO}}, D R E_{S}^{\mathrm{GIRIO}}, F E_{S}^{\mathrm{GIRIO}}$ by origins by destinations, which precisely shows each country's different roles in $S^{\prime}$ exports production fragmentation.

Accurate calculation of carbon emissions and embodied carbon intensity in exports is important for understand carbon emissions responsibilities among producers and consumers in different countries, especially for large export-oriented economy. We further empirically compare the two approaches by decomposing carbon emissions and carbon intensity in China's exports.

\section{Empirical Results}

\subsection{Data}

We use the data from national input-output table (SRIO), world input-output table (GIRIO) and Environmental Accounts of WIOD database. Although household emission data are available, we focus on $\mathrm{CO}_{2}$ emission from production. To facilitate analysis, we merger 41 economies into 8 regions: Mainland China, the EU, USA, Canada (CAN), Australia (AUS), other emerging countries (Brazil, Russia, India, Indonesia, Mexico, Turkey; EMR), other East Asia countries or regions (Japan, Korea, Taiwan; OEA), and the rest of the world (ROW). Also, merge original sector 19, 20, 21 into retail and wholesale, merge original sector 34, 35 into Social and Private Service. New SRIO table contains 1 economy, 32 sectors; new GIRIO table contains 8 economies, each with 32 sectors. Then we use SRIO model and GIRIO model to analyze carbon emissions and carbon intensity in China's exports in 1995, 2000, 2005 and 2009.

\subsection{Carbon Emissions in China's Exports at National Level}

Shown by Table 1 and Table 2, there are differences by SRIO model and GIRIO model in estimation of carbon emissions in China's exports. And the discrepancies generally increased from 1995 to 2009. Specifically, by considering emissions firstly exported but finally returned home, and different technology in domestic and imported inputs, compared with SRIO model,

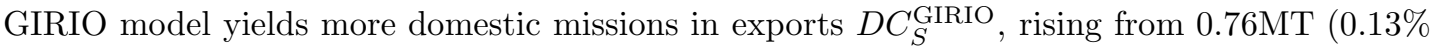
more than $\left.D C_{S}^{\mathrm{SRIO}}\right)$ in 1995 to $12.39 \mathrm{MT}(0.82 \%)$ in 2009 ; and less domestic emissions absorbed abroad $D C X_{S}^{\mathrm{GIRIO}}$, from $0.45 \%$ less than $D C_{S}^{\mathrm{SRIO}}$ in 1995 to $2.11 \%$ in 2009 ; bias of foreign emissions in exports $F C_{S}^{\text {GIRIO }}$ reaching to $85.2 \mathrm{MT}$ (over $5 \%$ of total emissions in exports) in 2009.

Of carbon emissions in China's exports by GIRIO model (Table 2), the majority is absorbed abroad $D C X_{S}^{\mathrm{GIRIO}}$, while embodied foreign emissions $F C_{S}^{\mathrm{SRIO}}$ still occupy a little share. But the structure is getting optimized, with rising domestic carbon emissions that finally return home $D R C_{S}^{\mathrm{GIRIO}}$ and embodied foreign emissions $F C_{S}^{\mathrm{GIRIO}}$. In detail, domestic carbon emissions exports $D C X_{S}^{\text {GIRIO }}$ multiplied 1.5 times from $593.77 \mathrm{MT}$ in 1995 to $1480.60 \mathrm{MT}$ in 2009. Though with declining ratio, $D C X_{S}^{\mathrm{GIRIO}}$ still takes up $90 \%$ of total carbon emissions in exports. Domestic emissions firstly exported but finally absorbed by home via imports $D R C_{S}^{\text {GIRIO }}$, in- 
creased in absolute quantity and relative share, from 3.45MT (0.56\%) in 1995 to $44.29 \mathrm{MT}$

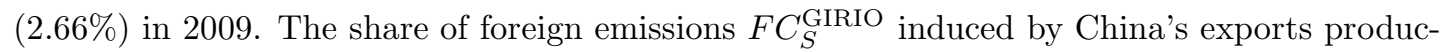
tion also rose sharply, from 41.99MT (6.51\%) in 2000 to $147.03 \mathrm{MT}$ (9.24\%) in 2009, indicating improvement of carbon emissions distribution in China's exports production fragmentation.

Table 1 Carbon emissions distribution in China's exports by SRIO model

\begin{tabular}{|c|c|c|c|c|c|c|c|c|c|}
\hline \multirow{2}{*}{\multicolumn{2}{|c|}{ Year }} & \multicolumn{3}{|c|}{$D C_{S}^{\mathrm{SRIO}}$} & \multicolumn{3}{|c|}{$F C_{S}^{\mathrm{SRIO}}$} & \multirow{2}{*}{\multicolumn{2}{|c|}{$\begin{array}{c}\text { Total } \\
\mathrm{MT} \mathrm{CO}_{2}\end{array}$}} \\
\hline & & \multicolumn{2}{|l|}{$\mathrm{MT} \mathrm{CO}_{2}$} & Share\% & \multicolumn{2}{|c|}{$\mathrm{MT} \mathrm{CO}_{2}$} & Share $\%$ & & \\
\hline \multicolumn{2}{|c|}{1995} & 596.46 & \multicolumn{2}{|c|}{95.55} & \multicolumn{2}{|c|}{27.79} & 4.45 & \multicolumn{2}{|c|}{624.25} \\
\hline \multicolumn{2}{|c|}{2000} & 601.29 & \multicolumn{2}{|c|}{95.76} & \multicolumn{2}{|l|}{26.6} & 4.24 & \multicolumn{2}{|c|}{627.89} \\
\hline \multicolumn{2}{|c|}{2005} & 1429.3 & \multicolumn{2}{|c|}{95.38} & \multicolumn{2}{|l|}{69.19} & 4.62 & \multicolumn{2}{|c|}{1498.49} \\
\hline \multicolumn{2}{|c|}{2009} & 1512.5 & \multicolumn{2}{|c|}{96.4} & \multicolumn{2}{|l|}{56.49} & 3.6 & \multicolumn{2}{|c|}{1568.99} \\
\hline \multirow[t]{2}{*}{ Year } & \multicolumn{2}{|c|}{$D C X_{S}^{\mathrm{GIRIO}}$} & \multicolumn{2}{|c|}{$D R C_{S}^{\mathrm{GIRIO}}$} & \multicolumn{2}{|c|}{$D C_{S}^{\text {GIRIO }}$} & \multicolumn{2}{|c|}{$F C_{S}^{\text {GIRIO }}$} & Total \\
\hline & $\mathrm{MT} \mathrm{CO}_{2}$ & Share\% & $\mathrm{MT} \mathrm{CO} \mathrm{CO}_{2}$ & Share\% & $\mathrm{MT} \mathrm{CO}_{2}$ & Share\% & $\mathrm{MT} \mathrm{CO}_{2}$ & Share\% & $\mathrm{MT} \mathrm{CO}_{2}$ \\
\hline 1995 & 593.77 & 96.31 & 3.45 & 0.56 & 597.22 & 96.87 & 20.45 & 3.31 & 617.68 \\
\hline 2000 & 595.96 & 92.42 & 6.9 & 1.07 & 602.86 & 93.49 & 41.99 & 6.51 & 644.85 \\
\hline 2005 & 1405.5 & 88.36 & 38.05 & 2.39 & 1443.55 & 90.75 & 147.03 & 9.24 & 1590.58 \\
\hline 2009 & 1480.6 & 88.84 & 44.29 & 2.66 & 1524.89 & 91.50 & 141.69 & 8.50 & 1666.58 \\
\hline
\end{tabular}

\subsection{China's Carbon Emissions Exports at Bilateral Level}

Table 3 illustrates China's domestic emissions absorbed by each country directly and indirectly $D C X_{S R}^{\mathrm{GIRIO}}$. Although USA and the EU remained major absorbers of carbon emissions in China's exports, rising demand from other emerging countries (EMR) in absolute amount and relative share needs to be emphasized.

In 1995, about 157.34MT (25.47\%) domestic emissions are "consumed" by USA, and 138.16 MT (22.37\%) by the EU. The amounts increased rapidly to $343.99 \mathrm{MT}$ (20.64\%), 327.02MT (20.64\%) respectively in 2009. It constitutes major parts of China's carbon emissions exports. Emissions exports to other East Asia (OEA) also increased in absolute amount but reduced in relative share, from 134.62MT (21.79\%) in 1995 to 201.13MT (12.07\%) in 2009. On the contrary, carbon emissions absorbed by other emerging countries (EMR) and rest of the world (ROW) increased steadily from $28.38 \mathrm{MT}$ (4.59\%), 103.95 (16.83\%) in 1995 to $176.99 \mathrm{MT}(10.62 \%)$, 335.83MT $(20.15 \%)$ in 2009. It can be seen final destinations of China's carbon emissions in exports are slowly shifting from developed countries to other emerging countries. If China is to tackle the problem of carbon leakage, other emerging countries' demand cannot be neglected.

Figure 2 shows shares of China's carbon emissions exports to each country by GIRIO model, and corresponding direct bilateral exports shares. Contradiction of exports share change and carbon emissions exports share change indicates indirect emissions flows are concealed in direct trade relationships. Impressively, despite China's direct exports to EU reduced dramatically from $26.66 \%$ to $21.80 \%$ from 2000 to 2009 , share of carbon emissions exports to EU remained 
stable. Also, although exports share to USA remained the same from 2000 to 2009, share of carbon emissions exports to USA decreased dramatically. Possibly because besides carbon emissions leakage by direct exports, USA and the EU also absorb China's emission by importing from other countries; and carbon emissions in direct exports to USA and the EU may finally absorbed by other countries, all of which are indirect carbon emissions exports by third countries. It highlights our work in tracing emissions back to origins and final destinations in GIRIO model.

Table 3 Decomposition of China's carbon emissions exports by trade partners

\begin{tabular}{ccccccccc}
\hline \multirow{2}{*}{ Regions } & \multicolumn{2}{c}{1995} & \multicolumn{2}{c}{2000} & \multicolumn{2}{c}{2005} & \multicolumn{2}{c}{2009} \\
\cline { 2 - 9 } & $\mathrm{MT} \mathrm{CO}_{2}$ & Share\% & $\mathrm{MT} \mathrm{CO}_{2}$ & Share\% & $\mathrm{MT} \mathrm{CO}_{2}$ & Share\% & MT CO $_{2}$ & Share\% \\
\hline USA & 157.34 & 25.47 & 182.82 & 28.35 & 396.18 & 24.91 & 343.99 & 20.64 \\
EU & 138.16 & 22.37 & 132.98 & 30.62 & 302.33 & 19.01 & 327.02 & 19.62 \\
CAN & 17.95 & 2.91 & 18.00 & 2.79 & 45.54 & 2.86 & 50.14 & 3.01 \\
AUS & 14.45 & 2.34 & 12.86 & 1.99 & 35.97 & 2.26 & 48.96 & 2.94 \\
EMR & 28.38 & 4.59 & 32.83 & 5.09 & 110.63 & 6.96 & 176.99 & 10.62 \\
OEA & 134.62 & 21.79 & 123.83 & 19.20 & 237.41 & 14.93 & 201.13 & 12.07 \\
ROW & 103.95 & 16.83 & 94.43 & 14.64 & 281.48 & 17.70 & 335.83 & 20.15 \\
Total & 594.85 & 96.3 & 597.75 & 92.68 & 1409.54 & 88.63 & 1484.06 & 89.05 \\
\hline
\end{tabular}

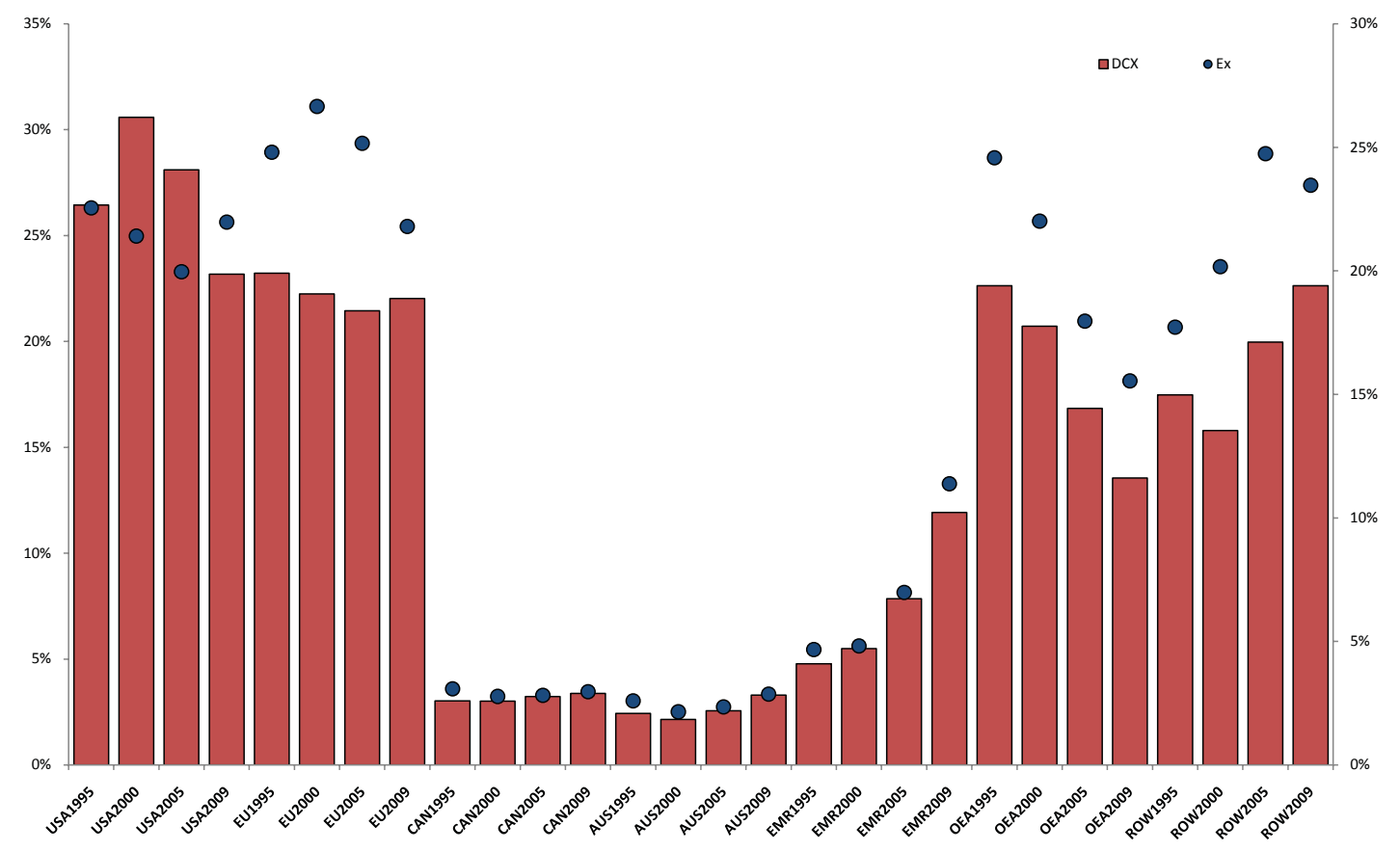

Figure 2 Share of China's domestic carbon emission exports to each country and exports to each country 


\subsection{China's Returned Carbon Emissions at Bilateral Level}

Table 4 shows domestic carbon missions firstly exported to each region but finally returned home via imports $D R C_{S R S}^{\mathrm{GIRIO}}$. Developing countries are making more and more contribution to China's exports production fragmentation and returned carbon emissions. In 1995, only 1.92MT domestic carbon emissions were firstly exported to OEA and EMR but finally returned back to China. Surprisingly, the amount rose sharply to $20.14 \mathrm{MT}$ in 2009 , exceeding contribution by USA and the EU (7.93MT). As developing countries are usually at processing in global supply chains, carbon emissions in exports to these countries are likely to be re-exported back to China or other countries.

Table 4 Decomposition of China's returned carbon emissions by trade partners

\begin{tabular}{ccccccccc}
\hline \multirow{2}{*}{ Regions } & \multicolumn{2}{c}{1995} & \multicolumn{2}{c}{2000} & \multicolumn{2}{c}{2005} & \multicolumn{2}{c}{2009} \\
\cline { 2 - 8 } & $\mathrm{MT} \mathrm{CO}_{2}$ & Share\% & $\mathrm{MT} \mathrm{CO}_{2}$ & Share\% & $\mathrm{MT} \mathrm{CO}_{2}$ & Share\% & MT CO $_{2}$ & Share\% \\
\hline USA & 0.42 & 0.07 & 0.34 & 0.05 & 1.90 & 0.12 & 5.24 & 0.31 \\
EU & 0.21 & 0.03 & 0.78 & 0.12 & 3.27 & 0.21 & 2.69 & 0.16 \\
CAN & 0.05 & 0.01 & 0.08 & 0.01 & 0.26 & 0.02 & 0.42 & 0.03 \\
AUS & 0.09 & 0.01 & 0.14 & 0.02 & 0.54 & 0.03 & 1.17 & 0.07 \\
EMR & 0.07 & 0.01 & 0.18 & 0.03 & 0.90 & 0.06 & 1.49 & 0.09 \\
OEA & 1.85 & 0.30 & 3.51 & 0.55 & 16.22 & 1.02 & 18.99 & 1.14 \\
ROW & 0.77 & 0.12 & 1.88 & 0.29 & 14.95 & 0.94 & 14.29 & 0.86 \\
Total & 3.45 & 0.56 & 6.90 & 1.07 & 38.05 & 2.39 & 44.29 & 2.66 \\
\hline
\end{tabular}

Table 5 Decomposition of foreign carbon emissions in China's exports by trade partners

\begin{tabular}{ccccccccc}
\hline \multirow{2}{*}{ Regions } & \multicolumn{2}{c}{1995} & \multicolumn{2}{c}{2000} & \multicolumn{2}{c}{2005} & \multicolumn{2}{c}{2009} \\
\cline { 2 - 8 } & $\mathrm{MT} \mathrm{CO}_{2}$ & Share\% & $\mathrm{MT} \mathrm{CO}_{2}$ & Share\% & $\mathrm{MT} \mathrm{CO}_{2}$ & Share\% & MT CO $_{2}$ & Share\% \\
\hline USA & 2.32 & 0.38 & 3.12 & 0.48 & 9.33 & 0.59 & 10.66 & 0.64 \\
EU & 2.31 & 0.37 & 4.29 & 0.67 & 13.01 & 0.82 & 11.44 & 0.69 \\
CAN & 0.62 & 0.10 & 0.90 & 0.14 & 2.41 & 0.15 & 2.69 & 0.16 \\
AUS & 0.79 & 0.13 & 1.79 & 0.28 & 4.83 & 0.30 & 5.70 & 0.34 \\
EMR & 3.26 & 0.53 & 6.03 & 0.93 & 22.13 & 1.39 & 23.77 & 1.43 \\
OEA & 4.88 & 0.79 & 10.92 & 1.69 & 34.86 & 2.19 & 33.34 & 2.00 \\
ROW & 6.28 & 1.02 & 14.93 & 2.32 & 60.46 & 3.80 & 54.09 & 3.25 \\
Total & 20.46 & 3.32 & 41.98 & 6.51 & 147.03 & 9.24 & 141.69 & 8.51 \\
\hline
\end{tabular}

\subsection{Foreign Carbon Emissions in China's Exports at Bilateral Level}

Table 5 shows foreign emissions in imported inputs in the production of China's exports, resembling China's carbon emission outsourcing. China mainly transfers environmental pressure in exports production to developing countries, with increasing trend during the period. Specifically, embodied emissions in China's exports from developing countries (EMR, OEA, 
ROW) amounted to $14.42 \mathrm{MT}$ in 1995, then rose sharply to $117.45 \mathrm{MT}$ in 2005 , but slightly fell down to 111.2MT (about 6.68\%) in 2009. Emissions from developed countries (USA, the EU, AUS and CAN) also increased to 30.49MT in 2009, but with low share (merely 1.83\%). Foreign emissions in China's exports reflect extension of global supply chains in China's production process, together with China's ability to transfer carbon emissions.

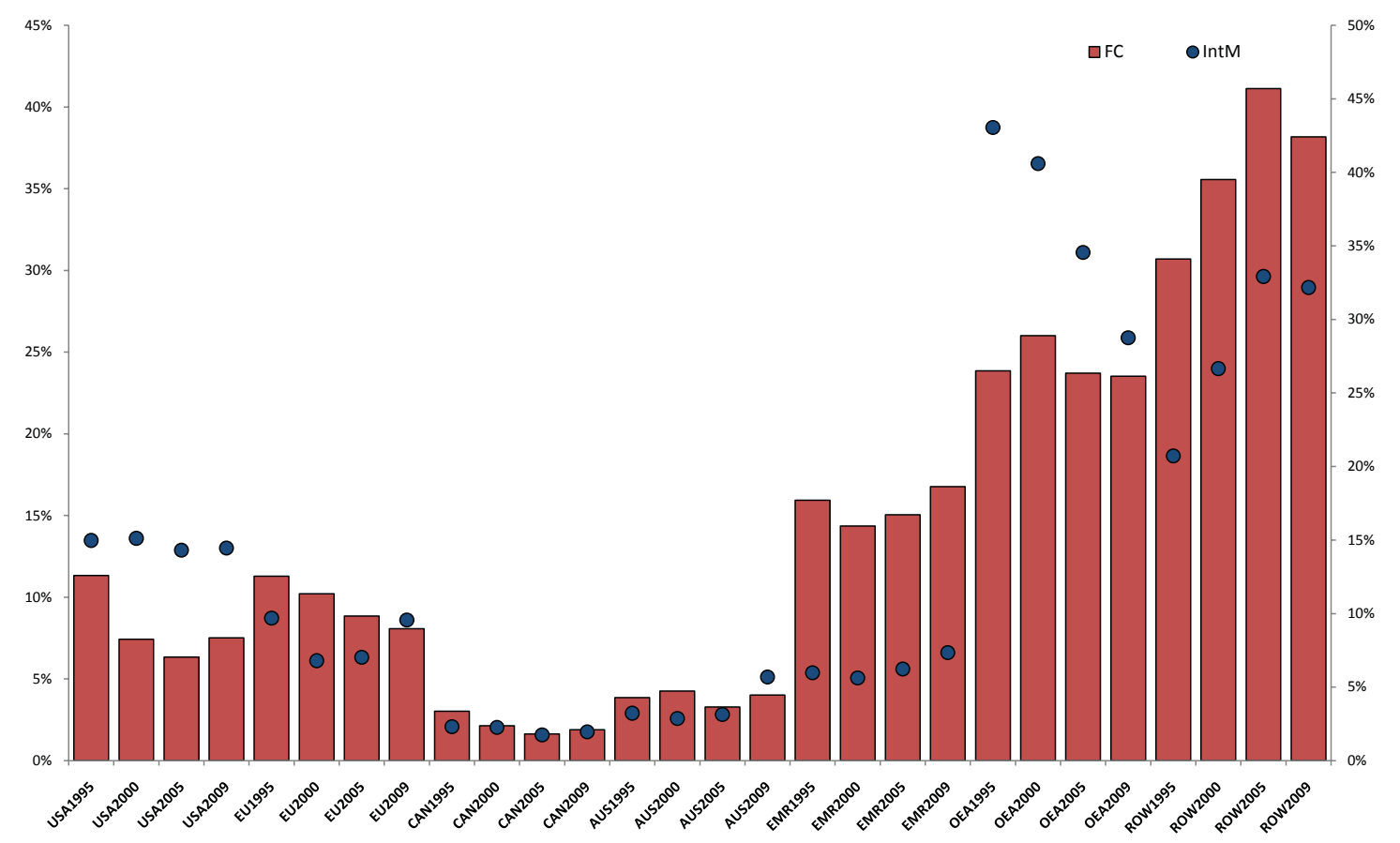

Figure 3 Share of China's carbon exports contain foreign parts from each country and intermediate import from each country

Figure 3 compares share of foreign emissions in China's exports based on GIRIO model, and share of imported intermediates goods. Different trends between the two estimations suggest origins of embodied foreign emissions in direct and indirect trade be traced under GIRIO model. Of foreign emissions in China's exports, carbon emissions from USA and the EU decreased from $11.34 \%, 11.29 \%$ in 1995 to $7.52 \%, 8.07 \%$ in 2009 respectively. However, share of intermediate imports from USA remained relatively stable, and intermediate imports from EU even rose from $6.8 \%$ in 2000 to $9.57 \%$ in 2009 . Also, carbon emissions from OEA in China's exports maintained at $24 \%$, while imported inputs from EA declined from $43.06 \%$ in 1995 to $28.76 \%$ in 2009.

Take EU for example, its exports may contain much foreign emissions, especially emissions from developing countries. It is actually other developing countries' carbon emissions exports to China via the EU. Therefore, despite growing direct exports, embodied carbon emissions from the EU in China's exports may even decline. Similarly, despite descending imports from EU, imported emissions in China's exports could probably increase by growing indirect carbon emissions exports. Under global production fragmentation, bilateral carbon emissions flows 
should be analyzed by tracing its origins in GIRIO model.

\subsection{Embodied Carbon Intensities in China's Exports}

Combing value-added gains and carbon emissions accounts in each component in exports, Table 6 compares environmental cost per value-added in exports production fragmentation in GIRIO and SRIO framework. Generally, domestic carbon intensity in exports in GIRIO model $D E_{S}^{\text {GIRIO }}$ is slightly higher than $D E_{S}^{\text {SRIO }}$ in SRIO model but with decreasing differences. The discrepancy decreased from $0.05 \mathrm{MT} \mathrm{CO}_{2}$ per billion dollars in 1995 to $0.02 \mathrm{MT} \mathrm{CO}_{2}$ per billion dollars in 2009. $F E_{S}^{\mathrm{SRIO}}$ is meaningless in SRIO model.

Despite dramatic decrease, $D E_{S}^{\mathrm{GIRIO}}$ is 1.52 times more than $F E_{S}^{\mathrm{GIRIO}}$, indicate in exports fragmentation, China specialized in high emissions but low value-added process, while foreign countries in "low-carbon but high value-added" production process.

Table 6 Embodied carbon intensity in exports from value-added perspective ( $\mathrm{MT} \mathrm{CO}_{2}$ /billion dollars)

\begin{tabular}{|c|c|c|c|c|c|}
\hline \multirow[t]{2}{*}{ Year } & \multicolumn{4}{|c|}{ GIRIO Approach } & \multirow{2}{*}{$\frac{\text { SRIO Approach }}{D E_{S}^{\text {GIRIO }}}$} \\
\hline & $D E X_{S}^{\mathrm{GIRIO}}$ & $D R E_{S}^{\mathrm{GIRIO}}$ & $D E_{S}^{\mathrm{GIRIO}}$ & $F E_{S}^{\mathrm{GIRIO}}$ & \\
\hline 1995 & 4.28 & 4.58 & 4.28 & 0.79 & 4.23 \\
\hline 2000 & 2.61 & 2.88 & 2.61 & 0.87 & 2.61 \\
\hline 2005 & 2.32 & 2.58 & 2.33 & 0.68 & 2.32 \\
\hline 2009 & 1.44 & 1.59 & 1.44 & 0.57 & 1.42 \\
\hline
\end{tabular}

Specifically, in $1995, D E_{S}^{\mathrm{GIRIO}}$ was $4.28 \mathrm{MT} \mathrm{CO}_{2}$ per billion dollars, over 5 times of $F E_{S}^{\text {GIRIO }}$. With technology improvements and official emphasis, $D E_{S}^{\text {GIRIO }}$ dropped to 1.44 MT $\mathrm{CO}_{2}$ per billion dollars, and $F E_{S}^{\mathrm{GIRIO}}$ decreased to $0.57 \mathrm{MT} \mathrm{CO}_{2}$ per billion dollars in 2009. Decrease of $D E_{S}^{\text {GIRIO }}$ was especially significant during 2005 to 2009, indicating China's progress in emission reduction during the 11th Five-Year Plan periods. To improve carbon emissions distribution, China still needs to move upstream and reduce emissions cost per GDP gained in exports production fragmentation.

\section{Conclusions and Suggestions}

This paper compares differences between SRIO model and GIRIO model in analyzing carbon emissions and embodied carbon intensity in exports under global fragmentation. Based on GIRIO model, decomposes carbon emissions and carbon intensities in exports by origin by destination along global supply chains.

Systematic comparison shows, by considering domestic emissions firstly exported but return home, and technology differences among imported inputs, GIRIO yields about $2.11 \%$ less domestic emissions absorbed abroad, $0.8 \%$ more domestic emissions in exports, 1.5 times more foreign emissions in exports than SRIO model in 2009. The discrepancies enlarged over the period. Different share changes between bilateral carbon emissions flows and bilateral trade flows indicate indirect carbon emissions transfer via third countries concealed in SRIO model, which requires tracing emissions by origin and destination in GIRIO model. 
As for carbon emissions flows, domestic emissions exports are mainly absorbed by USA, the EU though with declining trend. Share of domestic emissions exports to other emerging countries (EMR) increased during the period. Domestic emissions firstly exported to developing countries but finally returns home, and embodied emissions from developing countries in China's exports experienced rapid growth in absolute amount and relative share. Exports production fragmentation with developing countries contributes to China's carbon emissions outsourcing. In China's exports production fragmentation, China bears 1.52 times more carbon emissions emitted per GDP gained than foreign countries, despite dramatic decrease in absolute amount. China mainly specialize in "carbon intensive" process while imports relatively "value-added intensive" process.

We attempt to raise some useful suggestions with respect to carbon emissions in China's exports as follows.

1) Increase awareness of carbon emissions leakage. By indirect trade, developed countries absorb more carbon emissions, while China outsourcing more emissions to other East Asia countries. Developed countries should bear more responsibility for China's carbon emissions.

2) Optimize carbon emissions distribution by extending supply chains in exports production to developing countries. Carbon emissions in exports to these countries tend to return back or finally transfer to other countries. Cooperation with these countries will lessen China's carbon emissions burden, by outsourcing carbon emission-intensive process, though at the cost of lowskilled employment and value-added. Encouraging trade policy may be beneficial for China's carbon emissions distribution, and stimulate China's value chains upgrade.

3) Reduce carbon intensity to control emissions. China has participated in "low-value", "high-pollution" process. Embodied domestic carbon intensity drop during 2005-2009 indicated China's potential and intention in carbon emissions reduction and economic transformation. To move upwards in global supply chains, more effort is needed for reducing production fragment emissions while improving value-added gained in exports production fragmentation.

\section{References}

[1] Qiao H, Song N, Gao H W. Analysis on the strategies of European Union's airline carbon tax with Stackelberg game models. Systems Engineering — Theory \& Practice, 2014, 34(1): 158-167.

[2] Peters G P, Hertwich E G. $\mathrm{CO}_{2}$ embodied in international trade with implications for global climate policy. Environmental Science \& Technology, 2008, 42(5): 1401-1407.

[3] Weber C L, Peters G P, Guan D, et al. The contribution of Chinese exports to climate change. Energy Policy, 2008, 36(9): 3572-3577.

[4] Lin B, Sun C. Evaluating carbon dioxide emissions in international trade of China. Energy Policy, 2010, 38(1): 613-621.

[5] Minx J C, Baiocchi G, Peters G P, et al. A "carbonizing dragon": China's fast growing $\mathrm{CO}_{2}$ emissions revisited. Environmental Science \& Technology, 2011, 45(21): 9144-9153.

[6] Dong Y, Ishikawa M, Liu X, et al. An analysis of the driving forces of $\mathrm{CO}_{2}$ emissions embodied in JapanChina trade. Energy Policy, 2010, 38(11): 6784-6792.

[7] Du H, Guo J, Mao G, et al. $\mathrm{CO}_{2}$ emissions embodied in China-US trade: Input-output analysis based on the emergy/dollar ratio. Energy Policy, 2011, 39(10): 5980-5987.

[8] Los B, Timmer M P, de Vries G J. How important are exports for job growth in China? A demand side analysis. Journal of Comparative Economics, 2015, 43(1): 19-32.

[9] Weber C L, Matthews H S. Embodied environmental emissions in US international trade, 1997-2004. Environmental Science \& Technology, 2007, 41(14): 4875-4881. 
[10] Koopman R, Wang Z, Wei S J. Tracing value-added and double counting in gross exports. American Economic Review, 2014, 104(2): 459-494.

[11] Su B, Ang B W. Multi-region input-output analysis of $\mathrm{CO}_{2}$ emissions embodied in trade: The feedback effects. Ecological Economics, 2011, 71: 42-53.

[12] $\mathrm{Su} \mathrm{B}$, Ang B W. Input-output analysis of $\mathrm{CO}_{2}$ emissions embodied in trade: A multi-region model for China. Applied Energy, 2014, 114: 377-384.

[13] Wiedmann T. A review of recent multi-region input-output models used for consumption-based emission and resource accounting. Ecological Economics, 2009, 69(2): 211-222.

[14] Peters G P. From production-based to consumption-based national emission inventories. Ecological Economics, 2008, 65(1): 13-23.

[15] Peters G P, Andrew R, Lennox J. Constructing an environmentally-extended multi-regional input-output table using the GTAP database. Economic Systems Research, 2011, 23(2): 131-152.

[16] Timmer M P, Los B, Stehrer R, et al. Fragmentation, incomes and jobs: An analysis of European competitiveness. Economic Policy, 2013, 28(76): 613-661.

[17] Wang Z, Wei S J, Zhu K. Quantifying international production sharing at the bilateral and sector levels. National Bureau of Economic Research, 2013, No. w19677.

[18] Meng B, Peters G, Wang Z. Tracing $\mathrm{CO}_{2}$ emissions in global value chains. SSRN, 2014, http: //ssrn.com/ abstract $=2541893$.

[19] Zhang W, Peng S. Comparative analysis of "North" and "South" country's environmental pressure from consumption and production based perspectives. World Economy, 2014(8): 126-150.

[20] Xu Y, Dietzenbacher E. A structural decomposition analysis of the emissions embodied in trade. Ecological Economics, 2014, 101: 10-20.

[21] Xiao H, Yang J H, Qiao H. Quantification and decomposition of global carbon intensity induced by final demand. Systems Engineering — Theory \& Practice, 2015, 35(7): 1646-1656. 